\title{
Role of NF-kB and PPAR- $\gamma$ in lung inflammation induced by monocyte-derived microparticles
}

\author{
T. Neri*, C. Armani ${ }^{*}$, A. Pegoli*, C. Cordazzo*, Y. Carmazzi*, S. Brunelleschi", \\ C. Bardelli ${ }^{\mp}$, M.C. Breschi ${ }^{+}$, P. Paggiaro* and A. Celi*
}

ABSTRACT: Microparticles (MP) are phospholipid vesicles shed by cells upon activation or apoptosis. Monocyte-derived MP upregulate the synthesis of proinflammatory mediators by lung epithelial cells; the molecular bases of such activity are unknown. Peroxisome proliferatoractivated receptors (PPAR) have been demonstrated to be involved in the modulation of nuclear factor (NF)-KB transcriptional activity and inflammation.

We investigated whether the upregulation of the synthesis of proinflammatory cytokines by human lung epithelial cells induced by monocyte/macrophage-derived MP involves NF-kB activation and is modulated by PPAR- $\gamma$.

MP were generated by stimulation of human monocytes/macrophages with the calcium ionophore, A23187. MP were incubated with human lung epithelial cells. NF-кB translocation was assessed by electrophoretic mobility shift assay. Interleukin (IL)-8 and monocyte chemotactic protein (MCP)-1 synthesis was assessed by ELISA and RT-PCR.

Stimulation of $A 549$ alveolar cells with monocyte/macrophage-derived MP caused an increase in NF-KB activation and IL-8 and MCP-1 synthesis that was inhibited by pre-incubation with the PPAR- $\gamma$ agonists, rosiglitazone and 15-deoxy- $\Delta^{12,14}$-prostaglandin- $J_{2}$. Parallel experiments with normal human bronchial epithelial cells largely confirmed the results. The effects of PPAR- $\gamma$ agonists were reversed by the specific antagonist, GW9662.

Upregulation of the synthesis of proinflammatory mediators by human lung epithelial cells induced by monocyte/macrophage-derived MP is mediated by NF-кB activation through a PPAR- $\gamma$ dependent pathway.

KEYWORDS: Chemokines, $15-$ deoxy- $-\Delta^{12},{ }^{14}$-prostaglandin- $J_{2}$, lung inflammation, microparticles, peroxisome proliferator-activated receptors, rosiglitazone.

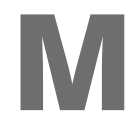
icroparticles (MP) are phospholipid vesicles shed by cells upon activation or during apoptosis. MP range in size from $50 \mathrm{~nm}$ to $1 \mu \mathrm{m}$ [1]. Evidence gathered over the past several years has demonstrated that MP are involved in numerous physiological processes, including blood coagulation and inflammation. Because of the presence of negatively charged phospholipids on the outer leaflet of MP, these structures have been long attributed a role in blood coagulation, a process that requires the assembly of multimolecular complexes on the surface of negatively charged phospholipid membranes. More recently, however, it has become evident that MP also carry other components of the parental cell besides the phospholipids, which greatly broaden the spectrum of their potential effects as intercellular mediators [1].
For example, the presence in monocyte-derived MP of tissue factor, an essential cofactor for the initiation of blood coagulation [2], adds to their role in blood coagulation and thrombus formation [3].

The role of leukocyte- and endothelial cellderived MP in inflammation has also been extensively investigated. MP released by stimulated polymorphonuclear leukocytes, for example, upregulate interleukin (IL)-6 and IL-8 synthesis by endothelial cells [4], while MP derived from T-lymphocytes and monocytes induce the synthesis of matrix metalloproteinases and cytokines by synovial fibroblasts [5].

We have previously demonstrated that stimulation of human monocytes/macrophages with the calcium ionophore, A23187, or with histamine,
AFFILIATIONS

*Dipartimento Cardiotoracico e

Vascolare, Laboratory of Respiratory Cell Biology,

\# Dipartimento Cardiotoracico e

Vascolare, Cardiovascular Research Laboratory,

+Dipartimento di Psichiatria, Neurobiologia, Farmacologia e Biotecnologie, University of Pisa, Pisa, and

-Dipartimento di Scienze Mediche, University of Piemonte Orientale A Avogadro, Novara, Italy.

\section{CORRESPONDENCE}

A. Celi, Dipartimento Cardiotoracico e Vascolare dell'Università di Pisa, Via Paradisa, 256124 Pisa, Italy, E-mail

alessandro.celi@med.unipi.it

Received:

Feb 112010

Accepted after revision:

Oct 282010

First published online:

Dec 092010 
causes MP shedding, and that incubation of these MP with lung epithelial cells results in upregulation of proinflammatory mediator synthesis, including IL-8 and monocyte chemotactic protein (MCP)-1 [6]. IL-8 is a potent chemoattractant for neutrophils involved in the pathogenesis of the inflammatory response typical of chronic obstructive pulmonary disease (COPD). IL-8 concentration increases in bronchoalveolar lavage fuid of COPD patients and correlates with neutrophil count and myeloperoxidase concentration [7]; furthermore, in a phase 2 trial, a monoclonal antibody to IL- 8 has been shown to reduce dyspnoea in COPD patients [8]. MCP-1, a chemoattractant for monocytes, has also been implicated in the pathogenesis of COPD and its concentration has been shown to increase in sputum of COPD patients compared with "healthy" smokers and nonsmokers [9]. Thus, the upregulation of IL-8 and MCP-1 synthesis induced by MP might contribute to the pathogenesis of COPD. However, the molecular bases of this activity of MP are not known.

Peroxisome proliferator-activated receptors (PPAR) are ligandactivated transcription factors belonging to the nuclear hormone receptor superfamily. Three isoforms of PPAR have been identified to date: $\alpha, \beta / \delta$, and $\gamma$. Originally identified for their role in lipid and glucose regulation, PPAR have more recently been implicated in the regulation of other phenomena, including inflammation [10]. PPAR- $\gamma$ is expressed, among other cell types, by alveolar and bronchial epithelial cells and its activation results in downregulation of proinflammatory mediator production, at least in part through suppression of nuclear factor (NF)- $\mathrm{BB}$ transcriptional activity [11, 12]. Accordingly, PPAR $-\gamma$ is currently being considered as a potential novel therapeutic target in COPD [13].

Here, we demonstrate that the effect of monocytes/ macrophage-derived MP on lung epithelial cell inflammation is mediated through $\mathrm{NF}-\kappa \mathrm{B}$ activation and is inhibited by PPAR- $\gamma$ stimulation.

\section{MATERIALS AND METHODS}

\section{Reagents and kits}

RPMI 1640 medium, Ham's F-12 medium, penicillin, streptomycin, L-glutamine, trypsin/EDTA, trypsin inhibitor, trypan blue, bovine serum albumin, PBS, dimethylthiazolyldiphenyltetrazolium bromide (MTT), Ficoll-Hypaque, dextran, calcium ionophore A23187, fetal bovine serum (FBS), ethidium bromide, agarose, REDTaq genomic DNA Polymerase SuperPaK, DNA ladder direct-load $100 \mathrm{bp}$ and anti-cytokeratin peptide18 antibodies were obtained from Sigma (Milan, Italy). iScript cDNA synthesis Kit and iQ SYBR green supermix were obtained from Bio-Rad (Hercules, CA, USA). NucleoSpin RNA II was obtained from Machery-Nagel (Duren, Germany). BEGM Bullet Kit was obtained from Cambrex (Caravaggio, BG, Italy). Rosiglitazone (Rz), 15-deoxy- $\Delta^{12,14}$ prostaglandin- $\mathrm{J}_{2}\left(15 \mathrm{dPgJ}_{2}\right)$ and $\mathrm{GW} 9662(\mathrm{GW})$ were obtained from Cayman Chemical (Ann Arbor, MI, USA). The human IL-8 cytoset, the human MCP-1 cytoset and the substrate 3,3',5,5'-tetramethylbenzidine were obtained from Biosource International (Camarillo, CA, USA). Nuclear Extract Kit was obtained from Active Motif (Rixensart, Belgium). All other chemicals were obtained from the hospital pharmacy and were of the best grade available.

\section{Real-time PCR primers}

The sense and antisense primers for human IL-8, MCP-1 and hypoxanthine-guanine phosphoribosyltransferase (HPRT) were obtained from Invitrogen (Milan, Italy) and had the following sequences:

IL-8 sense 5'GAATGGGTTTGCTAGAATGTGATA3' and antisense 5'CAGACTAGGGTTGCCAGATTTAAC3'; MCP-1 sense 5'CATTGTGGCCAAGGAGATCTG3' and antisense 5'CTTCG GAGTTTGGGTTTGCTT3'; and HPRT sense 5'AGACTTTGC TTTCCTTGGTCAGG3' and antisense 5'GTCTGGCTTATATC CAACACTTCG3'.

\section{Cell culture}

Cells of the human alveolar epithelial line, A549, (CCL-195, American Type Culture Collection, Manassas, VA, USA), were kindly provided by R. Danesi, University of Pisa, Pisa, Italy. A549 cells were maintained in RPMI supplemented with $10 \%$ (volume/volume) $\mathrm{FBS}, 100 \mathrm{U} \cdot \mathrm{mL}^{-1}$ of penicillin, and $100 \mu \mathrm{g} \cdot \mathrm{mL}^{-1}$ of streptomycin in a humidified $95 \%$ air and $5 \%$ $\mathrm{CO}_{2}$ atmosphere at $37^{\circ} \mathrm{C}$. The immortalised bronchial epithelial cells, BEAS-2B (American Type Culture Collection, CRL-9609), were kindly provided by S. Carnevali, University of Modena, Modena, Italy. BEAS-2B cells were maintained in 50\% RPMI 1640 and $50 \%$ BEGM in a humidified $95 \%$ air and $5 \% \mathrm{CO}_{2}$ atmosphere at $37^{\circ} \mathrm{C}$.

Human bronchial epithelial cells (HBEC) were obtained from subjects undergoing diagnostic bronchoscopy as previously described. Briefly, after the patient's informed consent to the procedure was received, the fibreoptic bronchoscope was positioned at the level of the carina and/or the level of second- or third-order bronchial branchings. The use of local anaesthetics was kept as low as possible to minimise their effects on cell viability. Four to six brushings of grossly normal bronchial mucosa were regularly obtained. The cells were then removed from the brush by vortexing in Ham's F-12 medium$10 \%$ FBS. The cells were brought to the laboratory in ice and incubated with DNase $\left(50 \mathrm{mg} \cdot \mathrm{mL}^{-1}\right)$ to eliminate clumping. After a wash with ice-cold, serum-free Ham's F-12 medium, the cells were resuspended in BEGM and plated on Vitrogen 100-coated culture flasks (Santa Cruz Biotechnology, Santa Cruz, CA, USA). Indirect immunofluorescence with anticytokeratin antibodies confirmed the epithelial origin of the cells [14]. Cells used in the specific experiments reported here were obtained from a patient with peripheral lung cancer undergoing diagnostic bronchoscopy and were harvested from the contralateral main bronchus. The cells were used at passages three to four.

\section{Monocyte isolation and MP generation}

Monocytes were isolated either from fresh buffy coats obtained from the local blood bank or from the peripheral blood of normal volunteers as described. Briefly, a fresh buffy coat was diluted 1:1 with PBS-EDTA (2 mM), mixed gently with 0.25 volume of $2 \%$ Dextran T500 and left for $30 \mathrm{~min}$ for erythrocyte sedimentation. The leukocyte-rich supernatant was recovered and centrifuged for $10 \mathrm{~min}$ at $200 \times \mathrm{g}$. The pellet was resuspended in 30-mL of PBS-EDTA, layered over $15 \mathrm{~mL}$ of FicollHypaque and centrifuged for $30 \mathrm{~min}$ at $350 \times \mathrm{g}$ at $4^{\circ} \mathrm{C}$. The mononuclear cell-rich ring was recovered and washed twice in PBS-EDTA. Mononuclear cells were then resuspended in 
RPMI/10\% FBS and allowed to adhere for $18 \mathrm{~h}$ at $37^{\circ} \mathrm{C}$ on $24-$ well plates $\left(10^{6}\right.$ cells $\cdot$ well $\left.{ }^{-1}\right)$. Adherent cells were washed three times with pre-warmed serum-free RPMI. For MP generation, A23187 $(12 \mu \mathrm{M})$ was added; after $10 \mathrm{~min}$ at $37^{\circ} \mathrm{C}$, the supernatant was recovered, cleared by centrifugation at $14,000 \times \mathrm{g}$ for $5 \mathrm{~min}$ at room temperature to remove dead cells and big cell fragments that might have detached during the stimulation and immediately used for further experiments. In selected experiments, MP were further purified by ultracentrifugation $(100,000 \times \mathrm{g}$ for $2 \mathrm{~h})$; the pellet was resuspended in RPMI using the same volume as the original material. In parallel experiments, cells treated as described were detached by trypsin/ EDTA, put onto a slide using a cytocentrifuge and stained with Diff-Quick. Typically, 75-80\% cells were monocytes/macrophages, with the contaminants being mostly lymphocytes.

\section{Viability test}

The effect of different treatments on cell viability was determined by MTT assay. Cells were plated at $2.5 \times 10^{3}$ cells $\cdot$ well $^{-1}$ in $150 \mu \mathrm{L}$ of complete culture medium in 96-well microtitre plates for $24 \mathrm{~h}$. MTT $\left(5 \mathrm{mg} \cdot \mathrm{mL}^{-1}\right.$ in PBS) was then added to each well and incubated for $3 \mathrm{~h}$. The absorbance was recorded on a microplate reader (Titertek Multiskan MCC ELISA reader; Flow Laboratories, McLean, VA, USA) at the wavelength of $540 \mathrm{~nm}$. The effect of treatments on growth inhibition was expressed as per cent cell viability compared with untreated cells.

\section{Epithelial cell activation by MP}

Supernatants from A23187-stimulated or untreated monocytes/macrophages were incubated with A549, BEAS-2B cells

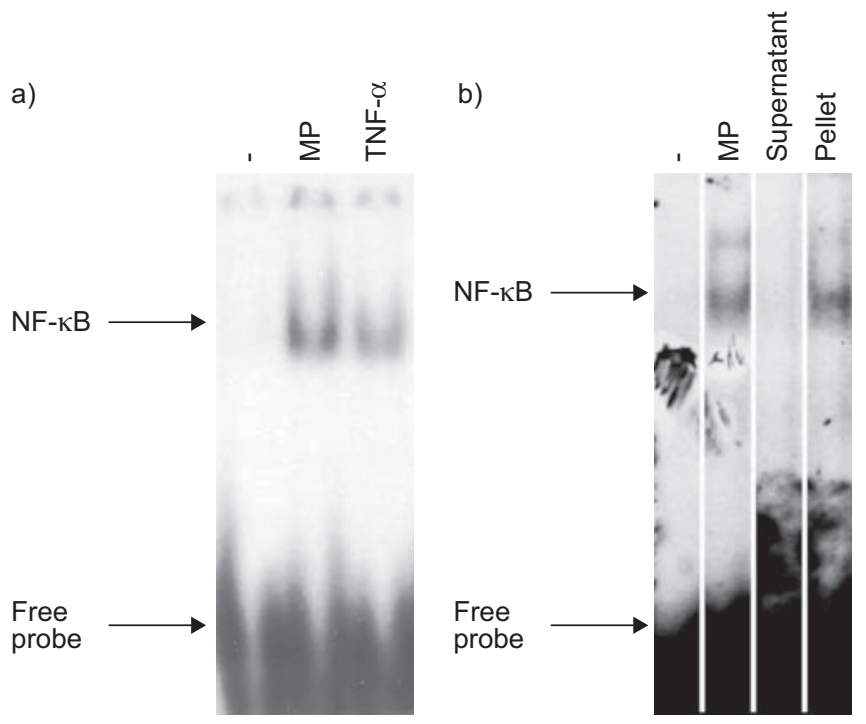

FIGURE 1. a) Nuclear factor (NF)-кB activation in A549 cells stimulated for $1 \mathrm{~h}$ with the supernatant from untreated monocytes/macrophages (-), or from A23187stimulated monocytes/macrophages (MP) or with tumour necrosis factor (TNF)- $\alpha$ $\left(1,000 \mathrm{U} \cdot \mathrm{mL}^{-1}\right)$. b) NF-KB activation in unstimulated A549 cells (-), in A549 cells treated with the supernatant of A23187-stimulated monocytes/macrophages (MP), with the supernatant of the same material after ultracentrifugation $(100,000 \times \mathrm{g}$ for $2 \mathrm{~h}$; supernatant) or with the pellet obtained after the ultracentrifugation reconstituted in the same volume of buffer as the starting material (pellet). Separate lanes of the same gel are shown. and HBEC, pretreated for $2 \mathrm{~h}$ with $\mathrm{Rz}$ or $15 \mathrm{dPg}_{2}$ or medium, grown to confluence in 96-well plates for $24 \mathrm{~h}$ at $37^{\circ} \mathrm{C}$. In some experiments, A549 cells were stimulated with tumour necrosis factor (TNF)- $\alpha\left(1,000 \mathrm{U} \cdot \mathrm{mL}^{-1}\right)$ instead of monocyte/macrophagederived supernatants. Following 18-h incubation, the conditioned medium was harvested, cleared by centrifugation for $5 \mathrm{~min}$ at $12,000 \times \mathrm{g}$ and analysed for IL- 8 and MCP-1 content.

\section{ELISA for chemokine detection}

IL-8 and MCP-1 in supernatants from A549, BEAS-2B and HEBC epithelial cells were measured by sandwich ELISA kits according to the manufacturers' instructions.

\section{RT-PCR}

RNA was extracted from the cells using the NucleoSpin RNA II (Machery-Nagel) according to the manufacturer's instructions, $18 \mathrm{~h}$ after MP stimulation. RNA concentration and purity were determined by spectrophotometric readings at 260/ $280 \mathrm{~nm}$. RNA was then either reverse transcribed to cDNA or stored at $-80^{\circ} \mathrm{C}$ for further uses. The RNA to cDNA reverse transcription was performed using Iscript cDNA synthesis Kit (Bio-Rad) according to the manufacturer's instructions.

RT-PCR was performed using IQ SYBR GREEN SUPERMIX (Bio-Rad) on the MiniOpticon Two-Colour Real-time PCR detection System (Bio-Rad). PCRs were performed in duplicate and HPRT was coamplified to normalise the amount of RNA added to the reaction. All data were analysed using the OpticonMonitor3 ${ }^{\circledR}$ software (Bio-Rad). To compare the expression of mRNA levels among different samples, the relative expression of mRNA levels was calculated using the comparative $\Delta C_{T}$ (threshold cycle number) method [15]. Briefly, the following formula was used: $2^{-\Delta \Delta C T}$, where $\Delta \Delta C_{T}$ is the difference in $C_{T}$ between the gene of interest and HPRT, and $\mathrm{C}_{\mathrm{T}}$ for the sample $=\mathrm{C}_{\mathrm{T}}$ for the actual sample $-\mathrm{C}_{\mathrm{T}}$ of the lowest expression sample. The amplification efficiencies of the primers pairs were determined by running serial dilutions of the cDNA. Both target and reference genes were amplified with efficiencies near $100 \%$ with a $\mathrm{R}^{2}$ value of 0.99 .

\section{Electrophoretic mobility shift assay}

After challenge with the appropriate stimuli, A549 cells $\left(2 \times 10^{6}\right)$ were washed with ice-cold PBS, scraped and centrifuged at $1,000 \times \mathrm{g}$ for $5 \mathrm{~min}$ at $4^{\circ} \mathrm{C}$. Nuclear extracts were obtained with a commercially available Kit (Nuclear Extract Kit; Active Motif) according to the manufacturer's instructions. Nuclear extracts $(5 \mu \mathrm{g})$ were incubated with $2 \mu \mathrm{g}$ poly $(\mathrm{dI}-\mathrm{dC})$ and the $\gamma\left[{ }^{32} \mathrm{P}\right]$ ATP-labelled oligonucleotide probe $(100,000-$ $150,000 \mathrm{cpm}$; Promega, Milan, Italy) in binding buffer $(50 \%$ glycerol,10 mM Tris- $\mathrm{HCl}$, pH 7.6, 500 mM KCl, 10 mM EDTA, $1 \mathrm{mM}$ dithiothreitol) in a final volume of $20 \mu \mathrm{L}$ for $30 \mathrm{~min}$ at room temperature. The NF- $\kappa \mathrm{B}$ consensus oligonucleotide (5'-AGTTGAGGGGACTTTCCCAGGC-3') was obtained from Promega. The nucleotide-protein complex was separated on a $5 \%$ polyacrylamide gel in $0.5 \times$ TBE buffer $(100 \mathrm{mM}$ Tris- $\mathrm{HCl}, 100 \mathrm{mM}$ boric acid, $2 \mathrm{mM}$ EDTA) at $150 \mathrm{~V}$ on ice. The gel was dried and radioactive bands were detected by autoradiography.

\section{Data presentation and statistical analysis}

Unless otherwise indicated, data are shown as mean \pm SEM from $\mathrm{n}$ independent, consecutive experiments; comparisons 

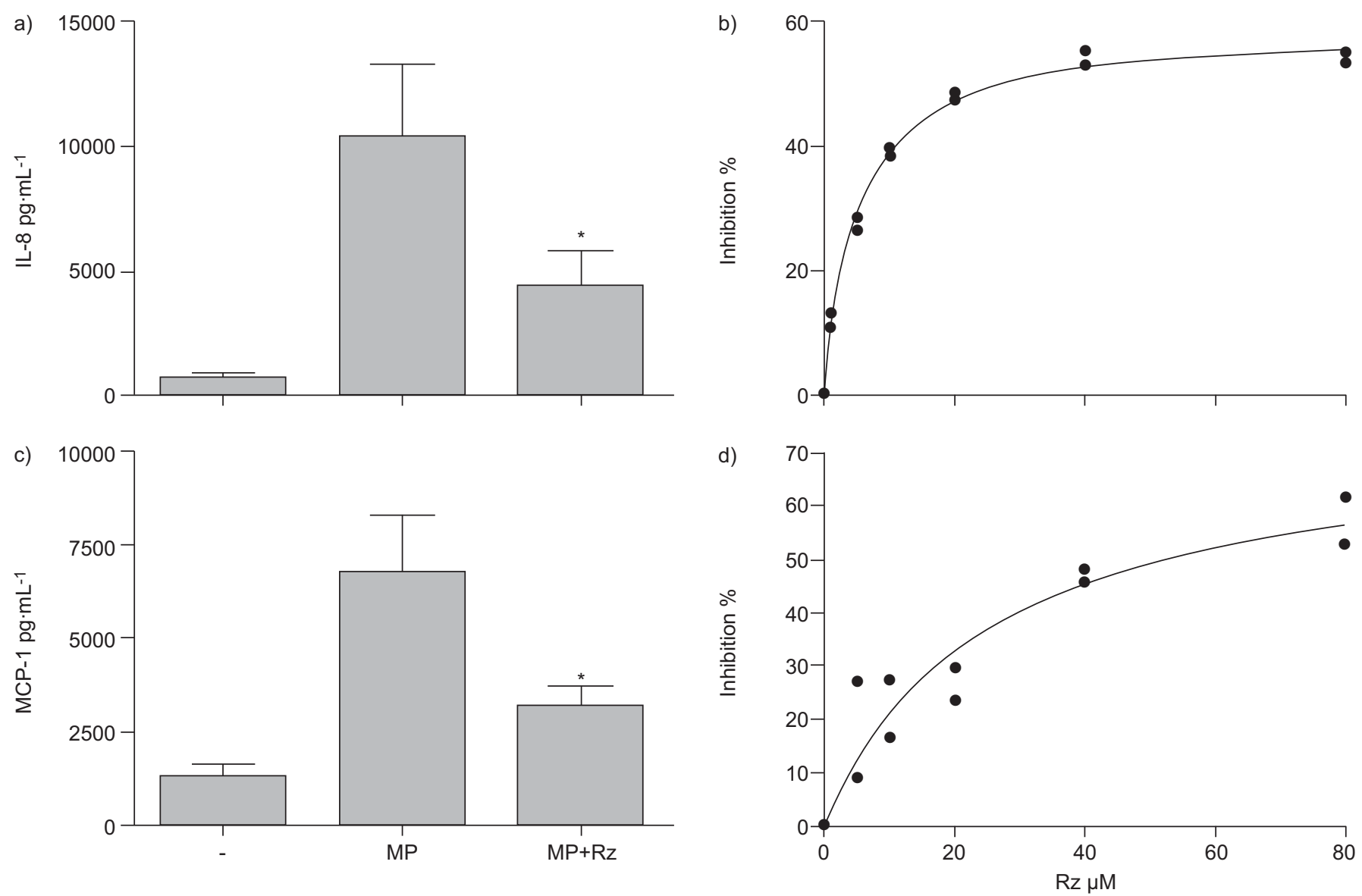

FIGURE 2. a) Interleukin (IL)-8 expression and c) monocyte chemotactic protein (MCP)-1 expression by A549 cells in baseline conditions (-), upon overnight incubation with monocyte/macrophage-derived microparticles (MP), and upon incubation with MP in the presence of $80 \mu M$ rosiglitazone $(M P+R z)$; $n=8$ and $n=10$, respectively. *: $p<0.05$ compared with MP-stimulated cells by ANOVA. Dose-response curve of Rz-mediated inhibition of b) IL-8 expression and d) MCP-1 expression by A549 stimulated with MP. Data from one experiment in duplicate representative of two others.

among groups were made by either ANOVA for repeated measurements followed by Bonferroni's analysis or paired t-test, using Prism Software (GraphPad, San Diego, CA, USA). Values of $\mathrm{p}<0.05$ were considered statistically significant.

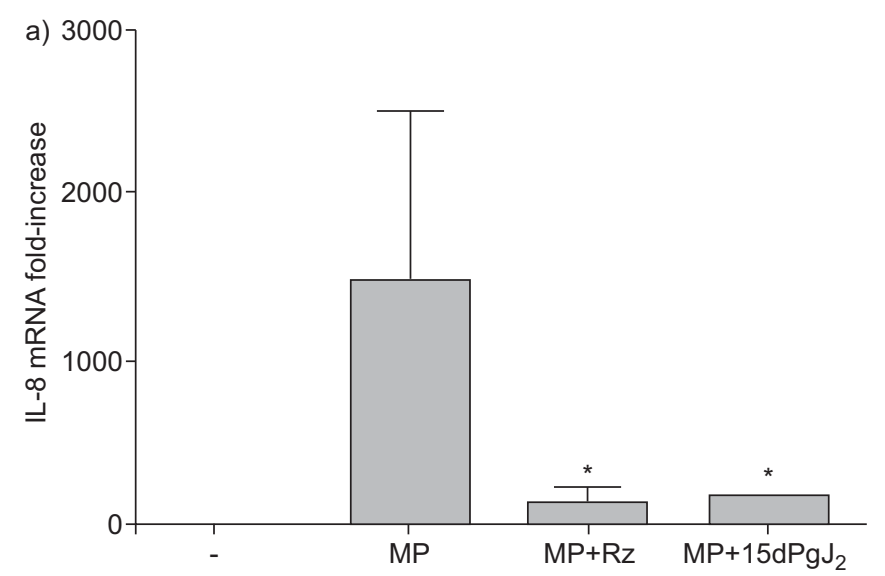

\section{RESULTS}

\section{MP-induced upregulation of chemokine synthesis by A549} cells is dependent on NF- $\kappa B$ activation

To investigate whether monocyte/macrophage-derived MP induce translocation of NF- $\kappa \mathrm{B}, \mathrm{A} 549$ cells were incubated with

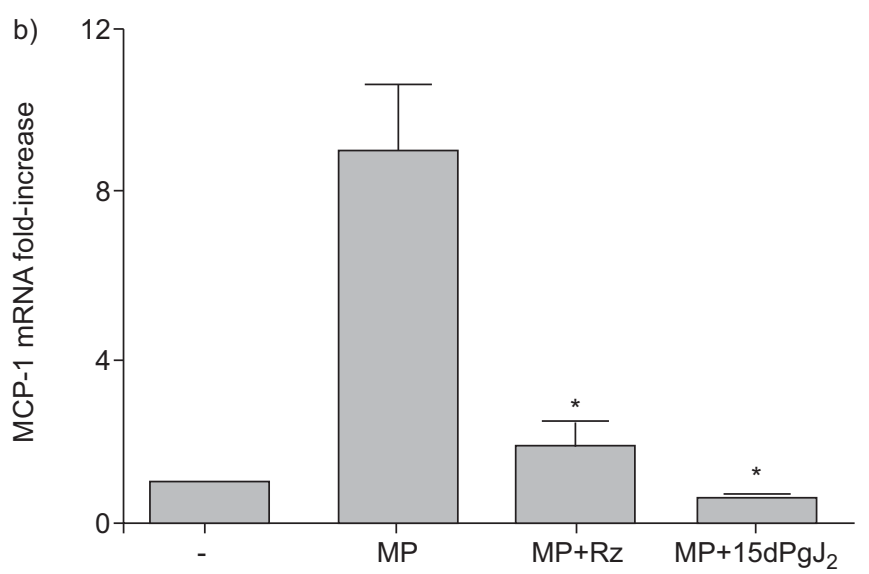

FIGURE 3. RT-PCR analysis for a) interleukin (IL)-8 and b) monocyte chemotactic protein (MCP)-1 mRNA content. MP: monocyte/macrophage-derived microparticles; Rz: rosiglitazone; $15 \mathrm{dPgJ}_{2}$ : $15-$ deoxy- $\Delta^{12,14}$-prostaglandin- $\mathrm{J}_{2}$. ${ }^{*}: \mathrm{p}<0.05$ by ANOVA; $n=3$. 


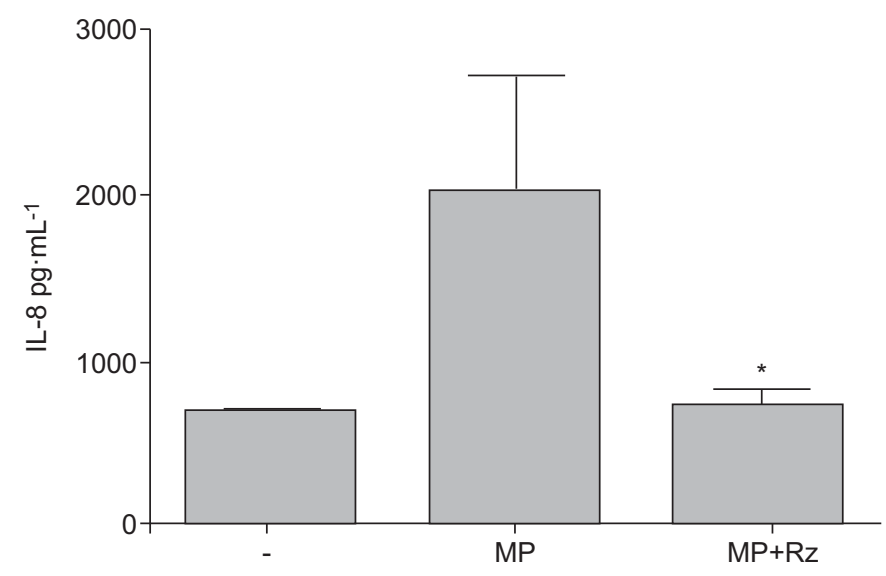

FIGURE 4. Interleukin (IL)-8 release by human bronchial epithelial cells in baseline conditions (-), upon overnight incubation with monocyte/macrophagederived microparticles (MP) and upon incubation with MP in the presence of $80 \mu \mathrm{M}$ rosiglitazone (MP+Rz). *: $p<0.05$ compared with MP-stimulated cells by ANOVA; $n=3$.
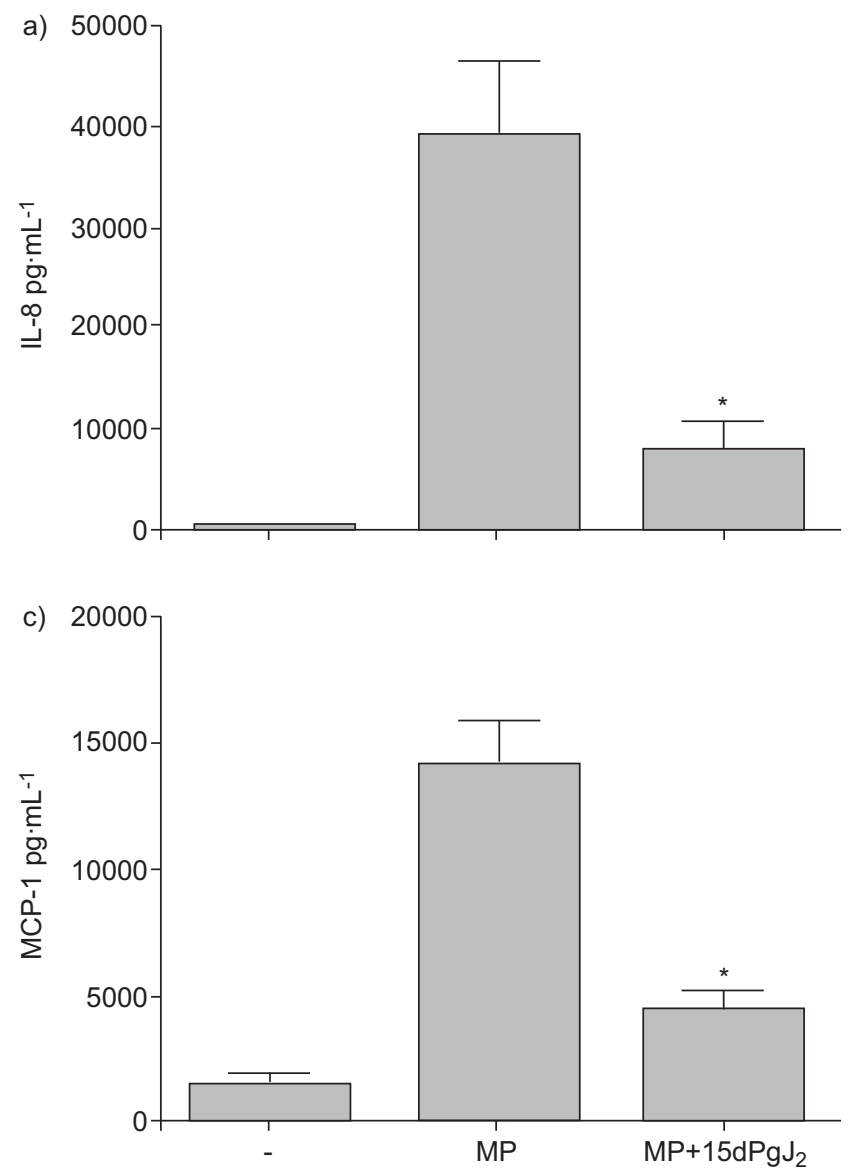

MP; nuclear extracts were then examined for electrophoretic shift. Figure 1a shows that MP-stimulated A549 cells undergo NF-кB activation. To confirm that MP, rather than soluble molecules, were responsible for such activation, MP-containing monocyte/ macrophage conditioned medium was submitted to ultracentrifugation $(100,000 \times \mathrm{g}$ for $2 \mathrm{~h})$. Figure $1 \mathrm{~b}$ shows that NF- $\mathrm{BB}$ activation is induced by the sedimented MP more intensely than by the supernatant. Since NF- $\kappa B$ was not detectable in unstimulated cells in most experiments, the effect of PPAR- $\gamma$ agonists on $\mathrm{NF}-\kappa \mathrm{B}$ in baseline conditions was not investigated.

PPAR- $\gamma$ activation inhibits MP-induced synthesis of IL-8 and MCP-1 by lung epithelial cells

Baseline synthesis of IL- 8 and MCP-1 by A549 cells was not significantly affected by $\mathrm{Rz}$ treatment $\left(938.5 \pm 303.3 \mathrm{pg} \cdot \mathrm{mL}^{-1}\right.$ versus $609.8 \pm 161.7 \mathrm{pg} \cdot \mathrm{mL}^{-1} ; \mathrm{n}=6$ and $1286 \pm 457.5 \mathrm{pg} \cdot \mathrm{mL}^{-1}$ versus $464.9 \pm 124.4 \mathrm{pg} \cdot \mathrm{mL}^{-1} ; \mathrm{n}=6$, respectively). Incubation of A549 cells with MP derived from A23187-stimulated human monocytes/macrophages induced the expression of both IL- 8 and MCP-1, as expected [6]. When the synthetic PPAR- $\gamma$ agonist, Rz, was added to A549 cells prior to incubation with MP, a statistically significant, dose-dependent decrease in the expression of IL-8 was observed (fig. 2a and b). The inhibition reached
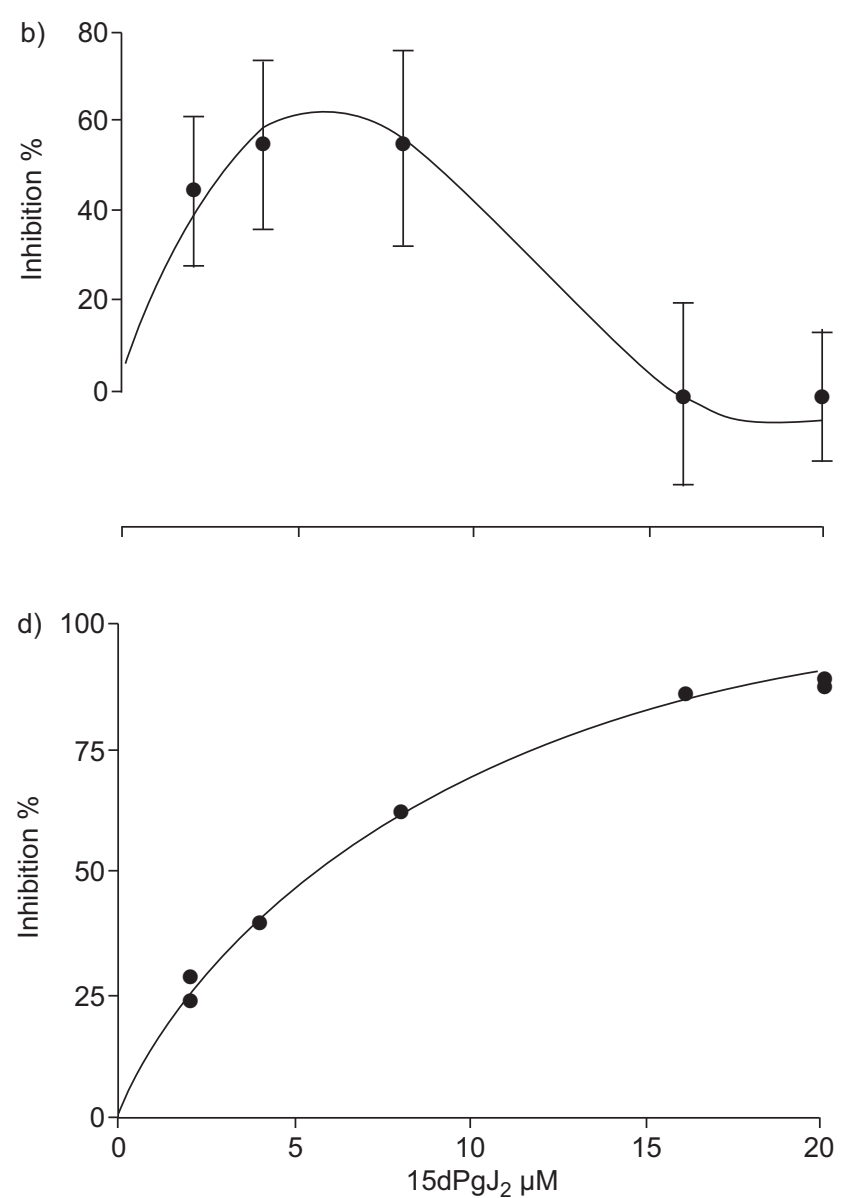

FIGURE 5. a) Interleukin (IL)-8 release and c) monocyte chemotactic protein (MCP)-1 expression by A549 cells in baseline conditions (-), upon overnight incubation with monocyte/macrophage-derived microparticles (MP), and upon incubation with MP in the presence of a) $8 \mu \mathrm{M}$ and c) $20 \mu \mathrm{M} 15-{ }_{-1 e o x y}-\Delta^{12,14}$-prostaglandin- $J_{2}\left(\mathrm{MP}+15 \mathrm{dPg} \mathrm{J}_{2}\right.$ ). * $: p<0.05$ compared with MP-stimulated cells by ANOVA; $n=3$ and $n=7$, respectively. Dose-response curve of $15 \mathrm{dPgJ}_{2}$-mediated inhibition of $b$ ) IL-8 expression ( $n=3$ ) and d) MCP-1 expression by A549 stimulated with MP. Data from one experiment representative of two. 


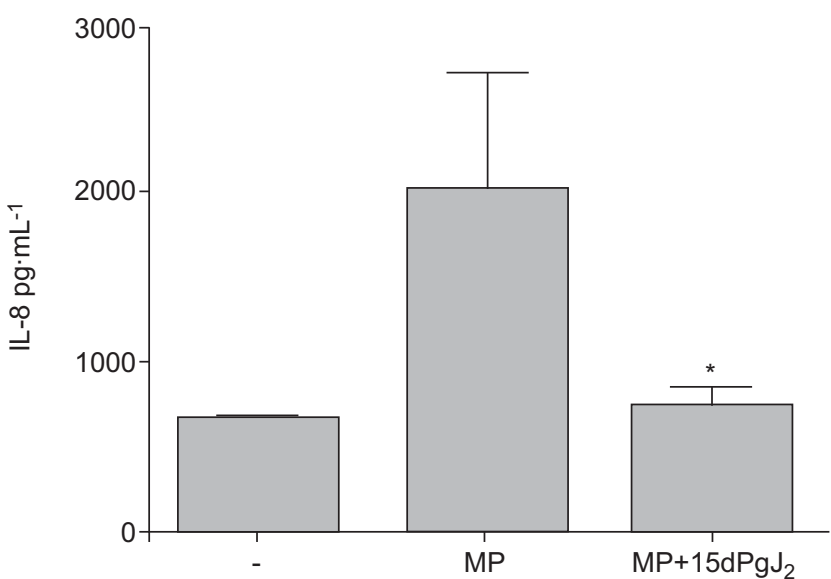

FIGURE 6. Interleukin (IL)-8 release by human bronchial epithelial cells in baseline conditions (-), upon overnight incubation with monocyte/macrophagederived microparticles (MP), and upon incubation with MP in the presence of $8 \mu \mathrm{M}$ 15-deoxy- $\Delta^{12,14}$-prostaglandin- $J_{2}\left(\mathrm{MP}+15 \mathrm{dPgJ} \mathrm{J}_{2}\right) .{ }^{*}: \mathrm{p}<0.05$ compared with MPstimulated cells by ANOVA; $n=3$. near maximum at $20 \mu \mathrm{M}$. In comparison, the inhibition of TNF- $\alpha-$ induced stimulation was less potent and required comparatively higher concentrations: a significant inhibition of IL-8 expression was reached at $80 \mu \mathrm{M} \mathrm{Rz}$ (data not shown). Similar results were obtained with the bronchial immortalised cell line, BEAS-2B (data not shown). A dose-dependent, significant reduction in MCP-1 synthesis was also observed (fig. $2 \mathrm{c}$ and $\mathrm{d}$ ). To evaluate whether the inhibitory effect of $\mathrm{Rz}$ was exerted at the transcriptional level, we performed quantitative RT-PCR. As shown in figure 3, preincubation of A549 cells with $\mathrm{Rz}(80 \mu \mathrm{M})$ or $15 \mathrm{dPgJ}_{2}(8 \mu \mathrm{M})$ caused a decrease in IL- 8 and MCP-1 mRNA. MTT tests confirmed that $\mathrm{Rz}$ did not affect A549 viability at concentrations up to $80 \mu \mathrm{M}$ (data not shown).

Figure 4 shows the effect of pre-incubation of HBEC with $\mathrm{Rz}$ prior to stimulation with $\mathrm{MP}$. $\mathrm{Rz}$ significantly inhibits MP induced IL- 8 synthesis by these cells. $\mathrm{Rz}$ at the concentrations used did not affect HBEC viability (data not shown).

To confirm that the observed inhibitory effects are not due to activities specific to $\mathrm{Rz}$, we used the naturally occurring,
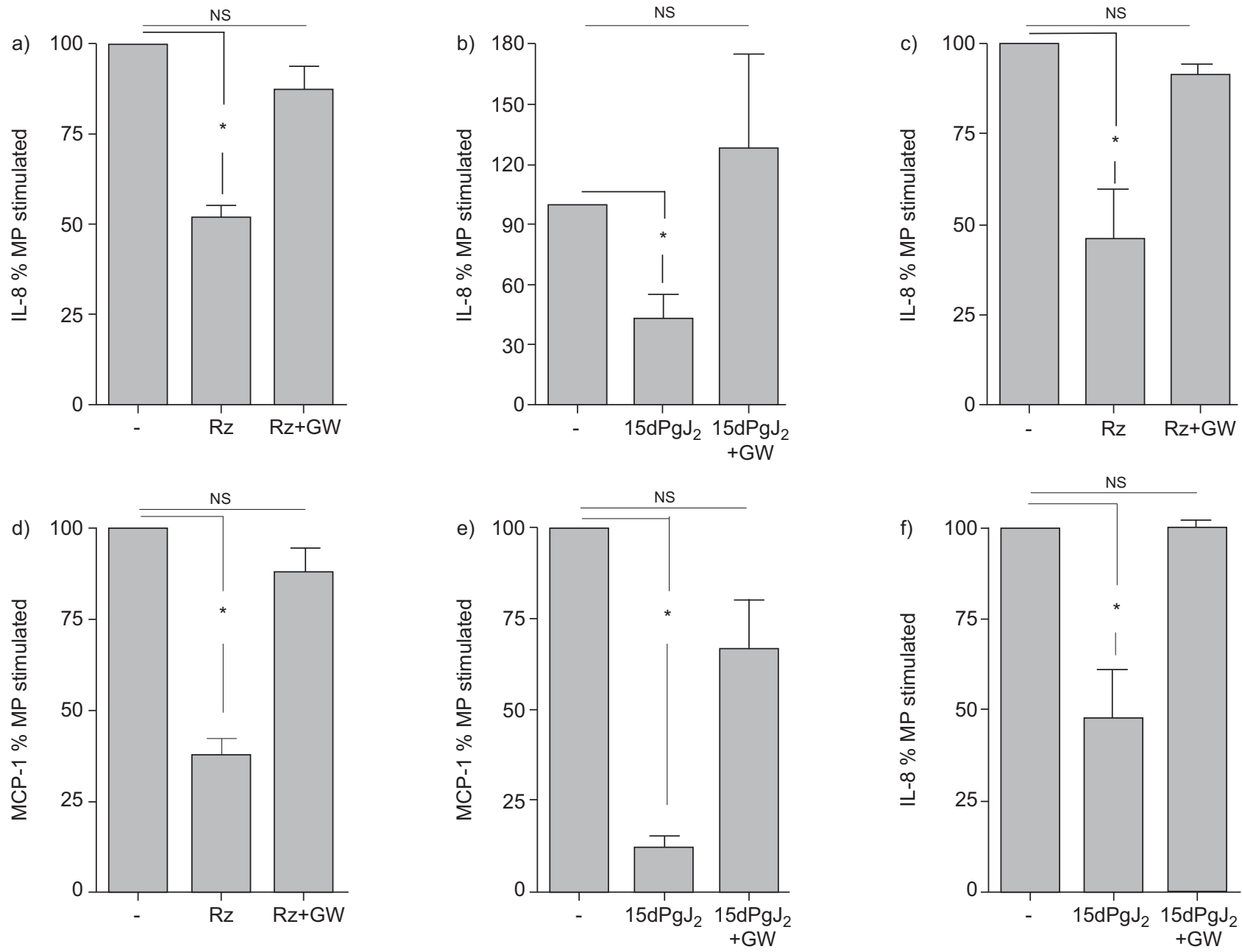

FIGURE 7. a, b) Interleukin (IL)-8 and d,e) monocyte chemotactic protein (MCP)-1 release by microparticle (MP)-stimulated A549 cells in the absence or presence of a and d) rosiglitazone $(\mathrm{Rz} ; 80 \mu \mathrm{M})$ or $\mathrm{b}$ and e) 15-deoxy- $\Delta^{12,14}$-prostaglandin- $\mathrm{J}_{2}\left(15 \mathrm{dPgJ} \mathrm{J}_{2} ; 8\right.$ and $20 \mu \mathrm{M}$, respectively), with or without the antagonist, GW9662 (GW) at equimolar concentrations. $c$ and f) IL-8 release by MP-stimulated human bronchial epithelial cells in the presence of either Rz $(80 \mu \mathrm{M})$ or $15 \mathrm{dPg} \mathrm{J}_{2}(8 \mu \mathrm{M})$, with or without the antagonist, GW. *: $p<0.05$ compared with MP-stimulated cells, paired t-test. NS: not significant; $\mathrm{n}=3$. 
structurally unrelated, PPAR- $\gamma$ activator, $15 \mathrm{dPgJ}_{2}$. As shown in figure $5,15 \mathrm{dPgJ}_{2}$ causes a significant decrease in both IL-8 (fig. 5a and b) and MCP-1 (fig. 5c and d) synthesis by A549 cells, respectively. Dose-response analysis, however, showed a dose-response relationship only for MCP-1 (fig. 5d) while inhibition of IL-8 expression induced by $15 \mathrm{dPgJ}_{2}$ appears biphasic, with maximal inhibition at $6-8 \mu \mathrm{g} \cdot \mathrm{mL}^{-1}$ and progressive loss of activity at higher concentrations (fig. 5b). MTT tests confirmed that $15 \mathrm{dPgJ}_{2}$ caused no significant loss of A549 cell viability at concentrations up to $20 \mu \mathrm{M}$.

Figure 6 shows the effect of pre-incubation of HBEC with $15 \mathrm{dPgJ}_{2}$ prior to stimulation with MP. $15 \mathrm{dPgJ}_{2}$ significantly inhibits MP-induced IL-8 synthesis by these cells. $15 \mathrm{dPgJ}_{2}$ at the concentrations used did not affect $\mathrm{HBEC}$ viability (data not shown).

Figure 7 shows that specific inhibition of PPAR- $\gamma$ activation with GW reverts the effects of both compounds on MPstimulated A549 (fig. 7a,b,c and d) and HBEC (fig. 7e and f).

Because it is possible that a minor effect on cell stimulation is due to soluble molecules present in the supernatant of stimulated monocytes/macrophages rather than to MP, we also repeated some of the experiments using MP purified by ultracentrifugation. Figure 8 shows that specific inhibition of PPAR- $\gamma$ activation reverts the effects of both compounds on A549 cells stimulated with MP purified by ultracentrifugation.

Figure 9 shows that both PPAR- $\gamma$ agonists inhibit NF- $\kappa B$ activation. Because both $\mathrm{Rz}$ and $15 \mathrm{dPgJ}_{2}$ have the potential to exert biological activities independent of PPAR- $\gamma$ activation [16-18], we sought to confirm the role of PPAR- $\gamma$ activation in the modulation of MP-induced lung epithelial cell inflammation using the specific PPAR- $\gamma$ inhibitor, GW. Figure 9 confirms that GW reverts the inhibitory effects of both PPAR- $\gamma$ agonists.

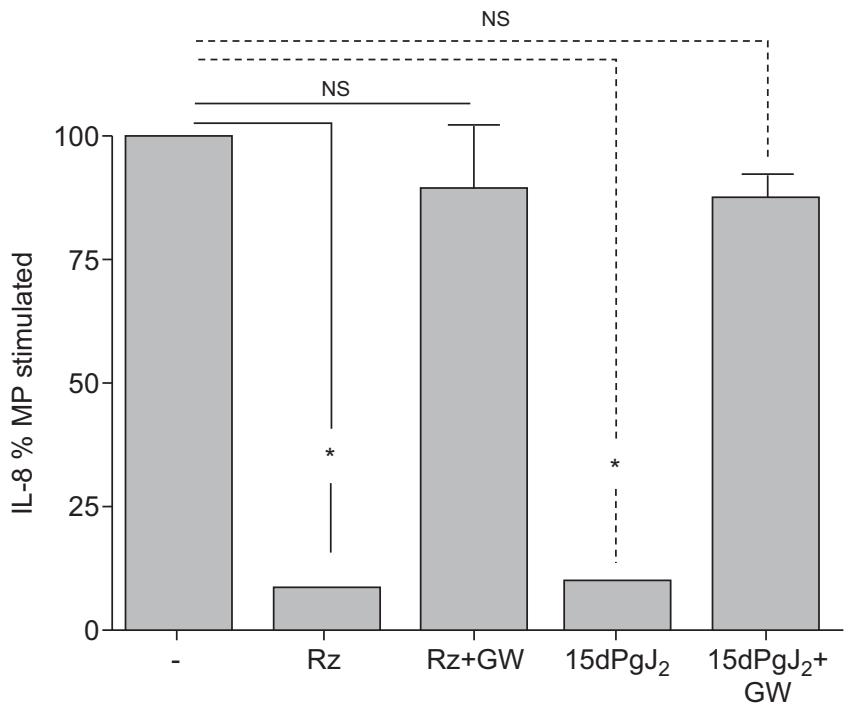

FIGURE 8. Interleukin (IL)-8 release by A549 cells stimulated by microparticles (MP) purified by ultracentrifugation in the absence or presence of either rosiglitazone $(\mathrm{Rz} ; 80 \mu \mathrm{M})$ or 15-deoxy- $\Delta^{12,14}$-prostaglandin- $\mathrm{J}_{2}\left(15 \mathrm{dPgJ}_{2} ; 8 \mu \mathrm{M}\right)$, with or without the antagonist, GW9662 (GW) at equimolar concentrations. *: $p<0.05$ compared with MP-stimulated cells, paired t-test. NS: not significant; $n=3$.

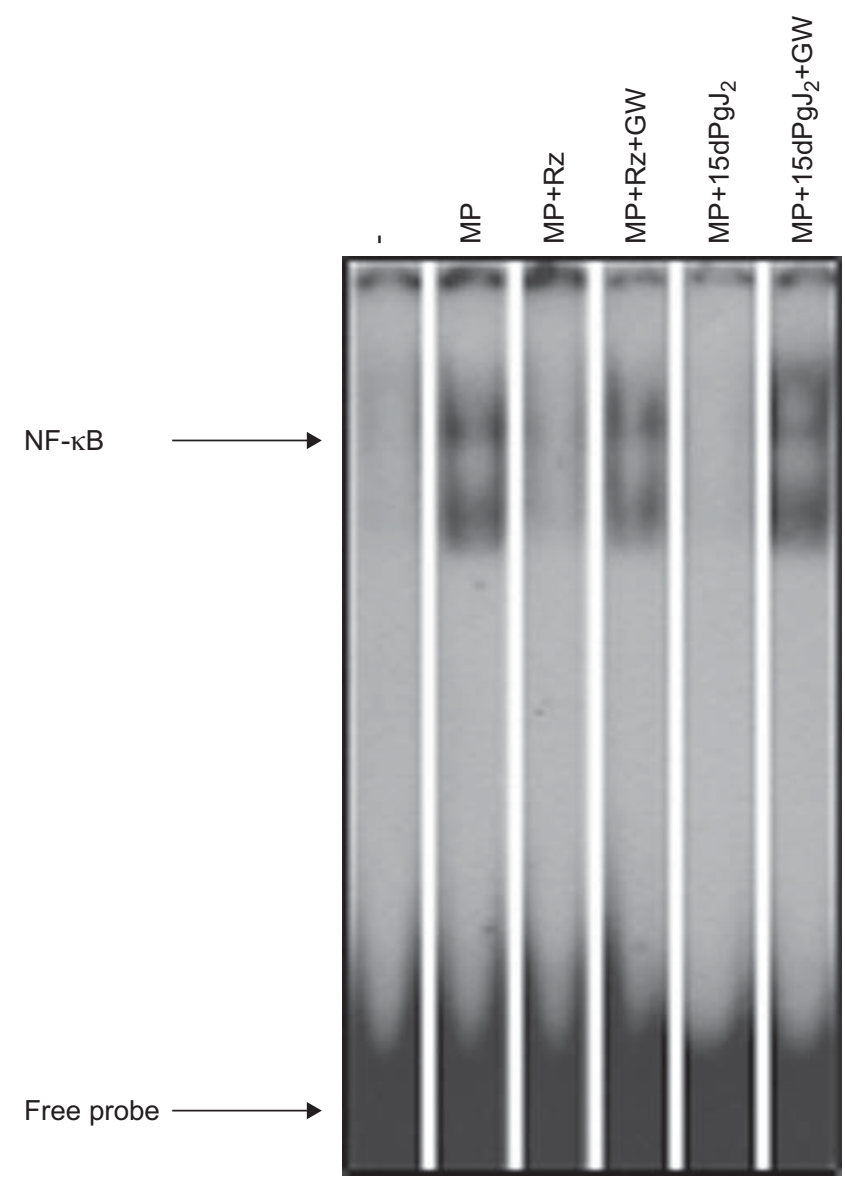

FIGURE 9. Nuclear factor (NF)- $\kappa B$ activation in A549 cells in baseline conditions (-), upon incubation with microparticles (MP), upon activation with MP after a $30 \mathrm{~min}$ pre-treatment with the peroxisome proliferator-activated receptor (PPAR)- $\gamma$ agonists 15-deoxy- $\Delta^{12,14}$-prostaglandin- $\mathrm{J}_{2}\left(15 \mathrm{dPg} \mathrm{J}_{2} ; 20 \mu \mathrm{M}\right)$ or rosiglitazone $(\mathrm{Rz} ; 80 \mu \mathrm{M})$ and upon activation with MP after a 30 min pre-treatment with the PPAR- $\gamma$ agonists $15 \mathrm{dPgJ}_{2}(20 \mu \mathrm{M})$ or Rz $(80 \mu \mathrm{M})$ in the presence of GW9662 (GW) (20 $\mu \mathrm{M}$ and $80 \mu \mathrm{M}$, respectively). Data from one experiment representative of three. Separate lanes of the same gel are shown.

\section{DISCUSSION}

Although originally thought to represent cell debris devoid of physiological significance, MP are now known to participate in different physiological phenomena. MP-mediated upregulation of the synthesis of proinflammatory agonists by endothelial cells and fibroblasts, for example, is becoming a well recognised determinant of inflammation [19]. As part of an attempt to further elucidate the mechanisms underlying MPinduced inflammation, the aim of the present study was to investigate the role of the PPAR- $\gamma$ pathway in the upregulation of cytokine synthesis by lung epithelial cells stimulated by monocyte/macrophage-derived MP.

Since it is known that PPAR- $\gamma$ activation suppresses NF- $\mathrm{B}$ / DNA binding, we first sought to determine whether MPinduced stimulation of lung epithelial cells was mediated through NF- $\mathrm{B}$ activation. Indeed, our data indicate that MP derived from monocytes/macrophages induces the translocation of NF- $\kappa \mathrm{B}$ into the nucleus; soluble molecules obtained after removal of the MP by ultracentrifugation had a much 
smaller effect. Using MP derived from polymorphonuclear cells, MESRI and ALTIERI [20] have shown that upregulation of IL-6 synthesis by endothelial cells does not involve NF- $\kappa B$ translocation into the nucleus. In contrast, in different in vivo and in vitro models, others have demonstrated a role for NF- $\kappa \mathrm{B}$ activation in MP-mediated inflammation [5, 21]. These apparently conflicting results probably reflect the fact that MP are heterogeneous in composition, depending on the cell from which they derive and on the stimulus used to induce their formation [22], and therefore exert their biological effect in different ways.

We then investigated the role of PPAR- $\gamma$ activation in our model. Our data indicate that the upregulation of proinflammatory mediators by human lung epithelial cells stimulated by monocyte/macrophage-derived MP is mediated through a PPAR- $\gamma$ dependent pathway. Two structurally unrelated PPAR- $\gamma$ agonists, the synthetic ligand $\mathrm{Rz}$, and the naturally occurring activator, $15 \mathrm{dPg}_{2}$, both inhibited NF- $\kappa B$ activation in A549 cells stimulated by monocyte/macrophage-derived MP. Both molecules also caused a significant inhibition in IL-8 expression by A549, BEAS-2B and HBEC cells stimulated by MP. MCP-1 synthesis was also significantly inhibited in A549 cells, while its expression in BEAS-2B cells was not investigated since we have confirmed our previous observation that this chemokine is not upregulated under the experimental conditions described. Of note, while the inhibitory effect of Rz was clearly dose-dependent in all the experimental models used, incubation of A549 cells with $15 \mathrm{dPgJ}_{2}$ caused an inhibition in IL-8 synthesis that was maximal at $6-8 \mu \mathrm{g} \cdot \mathrm{mL}^{-1}$ and became less potent at higher concentrations. It has been shown that $15 \mathrm{dPgJ}_{2}$ upregulates IL-8 (but not MCP-1) synthesis by monocytes/ macrophages [23] and by human microglia [24]. Although we have not directly addressed this issue, our results are consistent with a dual activity of $15 \mathrm{dPgJ}_{2}$ on MP-stimulated A549 cells, with an inhibitory effect that is eventually counterbalanced by a direct stimulatory activity at higher concentrations. Numerous reports have shown that thiazolidinediones exert their biological activities through both PPAR- $\gamma$-dependent and -independent pathways [16-18]. Our observation that the effect of both agonists is reverted by specific PPAR- $\gamma$ inhibition confirms that thiazolidinedione-mediated inhibition of the effects of MP on bronchial epithelial cells is PPAR- $\gamma$-dependent.

COPD is a pathological condition defined by the presence of chronic, progressive and mostly irreversible airflow limitation [25]. The disease is associated with an abnormal inflammatory response of the lungs to noxious particles or gases, cigarette smoke being the most important causative agent [25]. COPD is projected to become the third leading cause of death worldwide by the year 2020 [25]. While a combination of inhaled long-acting bronchodilators and steroids currently represents the mainstay therapy for COPD, the impact of this therapy on mortality is modest [26] and the need for a better understanding of the mechanisms of the disease and for new therapeutic approaches is clearly recognised [27]. PPARs have recently gained interest as modulators of the airway inflammatory reactions and are considered potential targets for the treatment of inflammatory lung disease [28]. Our data showing that PPAR- $\gamma$ agonists inhibit MP-induced epithelial inflammation lend further support to this approach.

\section{SUPPORT STATEMENT}

This study was supported by Ministero dell'Istruzione, dell'Università e della Ricerca of Italy, protocol number 20074S9KXF_002.

\section{STATEMENT OF INTEREST}

Statements of interest for S. Brunelleschi and P. Paggario can be found at www.erj.ersjournals.com/site/misc/statements.xhtml

\section{REFERENCES}

1 Hugel B, Martinez MC, Kunzelmann C, et al. Membrane microparticles: two sides of the coin. Physiology 2005; 20: 22-27.

2 Satta N, Toti F, Feugeas O, et al. Monocyte vesiculation is a possible mechanism for dissemination of membrane-associated procoagulant activities and adhesion molecules after stimulation by lipopolysaccharide. J Immunol 1994; 153: 3245-3255.

3 Celi A, Lorenzet R, Furie BC, et al. Microparticles and a P-selectinmediated pathway of blood coagulation. Dis Markers 2004; 20: 347-352.

4 Mesri M, Altieri DC. Endothelial cell activation by leukocyte microparticles. J Immunol 1998; 161: 4382-4387.

5 Distler JH, Jungel A, Huber LC, et al. The induction of matrix metalloproteinase and cytokine expression in synovial fibroblasts stimulated with immune cell microparticles. Proc Natl Acad Sci USA 2005; 102: 2892-2897.

6 Cerri C, Chimenti D, Conti I, et al. Monocyte/macrophage-derived microparticles up-regulate inflammatory mediator synthesis by human airway epithelial cells. J Immunol 2006; 177: 1975-1980.

7 Pesci A, Balbi B, Majori M, et al. Inflammatory cells and mediators in bronchial lavage of patients with chronic obstructive pulmonary disease. Eur Respir J 1998; 12: 380-386.

8 Mahler DA, Huang S, Tabrizi M, et al. Efficacy and safety of a monoclonal antibody recognizing interleukin-8 in COPD: a pilot study. Chest 2004; 126: 926-934.

9 Traves SL, Culpitt SV, Russell RE, et al. Increased levels of the chemokines GRO $\alpha$ and MCP-1 in sputum samples from patients with COPD. Thorax 2002; 57: 590-595.

10 Straus DS, Glass CK. Anti-inflammatory actions of PPAR ligands: new insights on cellular and molecular mechanisms. Trends Immunol 2007; 28: 551-558.

11 Hetzel M, Walcher D, Grub M, et al. Inhibition of MMP-9 expression by PPAR $\gamma$ activators in human bronchial epithelial cells. Thorax 2003; 58: 778-783.

12 Arnold R, Konig W. Peroxisome-proliferator-activated receptor- $\gamma$ agonists inhibit the release of proinflammatory cytokines from RSV-infected epithelial cells. Virology 2006; 346: 427-439.

13 Remels AH, Gosker HR, Schrauwen $\mathrm{P}$, et al. Peroxisome proliferator-activated receptors: a therapeutic target in COPD? Eur Respir J 2008; 31: 502-508.

14 Celi A, Cianchetti S, Petruzzelli S, et al. ICAM-1-independent adhesion of neutrophils to phorbol ester-stimulated human airway epithelial cells. Am J Physiol 1999; 277: L465-L471.

15 Livak KJ, Schmittgen TD. Analysis of relative gene expression data using real-time quantitative PCR and the 2(- $\Delta \Delta \mathrm{C}(\mathrm{T}))$ method. Methods 2001; 25: 402-408.

16 Galli A, Ceni E, Crabb DW, et al. Antidiabetic thiazolidinediones inhibit invasiveness of pancreatic cancer cells via PPAR $\gamma$ independent mechanisms. Gut 2004; 53: 1688-1697.

17 Derlacz RA, Hyc K, Usarek $\mathrm{M}$, et al. PPAR- $\gamma$-independent inhibitory effect of rosiglitazone on glucose synthesis in primary cultured rabbit kidney-cortex tubules. Biochem Cell Biol 2008; 86: 396-404.

18 Mughal RS, Warburton P, O'Regan DJ, et al. Peroxisome proliferator-activated receptor $\gamma$-independent effects of thiazolidinediones on human cardiac myofibroblast function. Clin Exp Pharmacol Physiol 2009; 36: 478-486. 
19 Ardoin SP, Shanahan JC, Pisetsky DS. The role of microparticles in inflammation and thrombosis. Scand J Immunol 2007; 66: 159-165.

20 Mesri M, Altieri DC. Leukocyte microparticles stimulate endothelial cell cytokine release and tissue factor induction in a JNK1 signaling pathway. J Biol Chem 1999; 274: 2311-2318.

21 Tesse A, Al-Massarani G, Wangensteen R, et al. Rosiglitazone, a peroxisome proliferator-activated receptor- $\gamma$ agonist, prevents microparticle-induced vascular hyporeactivity through the regulation of proinflammatory proteins. J Pharmacol Exp Ther 2008; 324: 539-547.

22 Bernimoulin M, Waters EK, Foy M, et al. Differential stimulation of monocytic cells results in distinct populations of microparticles. J Thromb Haemost 2009; 7: 1019-1028.

23 Zhang X, Wang JM, Gong WH, et al. Differential regulation of chemokine gene expression by 15-deoxy-delta 12,14 prostaglandin J2. J Immunol 2001; 166: 7104-7111.
24 Si Q, Zhao ML, Morgan AC, et al. 15-deoxy-Delta12,14-prostaglandin J2 inhibits IFN-inducible protein 10/CXC chemokine ligand 10 expression in human microglia: mechanisms and implications. J Immunol 2004; 173: 3504-3513.

25 Rabe KF, Hurd S, Anzueto A, et al. Global strategy for the diagnosis, management, and prevention of chronic obstructive pulmonary disease: GOLD executive summary. Am J Respir Crit Care Med 2007; 176: 532-555.

26 Calverley PM, Anderson JA, Celli B, et al. Salmeterol and fluticasone propionate and survival in chronic obstructive pulmonary disease. N Engl J Med 2007; 356: 775-789.

27 Sabroe I, Parker LC, Calverley PM, et al. Pathological networking: a new approach to understanding COPD. Thorax 2007; 62: 733-738

28 Belvisi MG, Hele DJ. Peroxisome proliferator-activated receptors as novel targets in lung disease. Chest 2008; 134: 152-157. 